\title{
Potential arsenic contamination in drinking water sources of Tanzania and its link with local geology
}

\author{
J. Ijumulana ${ }^{1,2}$, F. Mtalo $^{1} \&$ P. Bhattacharya ${ }^{2}$ \\ ${ }^{1}$ DAFWAT Research Group, Department of Water Resources Engineering, College of Engineering and Technology, \\ University of Dar es Salaam, Dar es Salaam, Tanzania \\ ${ }^{2}$ KTH-International Groundwater Arsenic Research Group, Department of Sustainable Development, \\ Environmental Science and Engineering, KTH Royal Institute of Technology, Stockholm, Sweden
}

\begin{abstract}
Recent studies on arsenic (As) occurrence particularly in African waters show that several sources of drinking water have elevated concentrations above national and international guidelines. In Tanzania, elevated concentrations of As above the WHO guideline $\left(10 \mu \mathrm{g} \mathrm{L}^{-1}\right)$ in Lake Victoria Gold fields is emerging as a threat to public health depending on groundwater and surface water as drinking water sources. In this study, spatial statistics and GIS tools have been used to delineate the relationship between As occurrence and local geological settings. Among the 12 mapped local geological units, the most targeted aquifers for potable water are characterized by granitoids, migmatite, mafic and ultramafic meta-sediments ( $\sim 50 \%$ of water points). The probability of having As levels above the WHO guideline was 0.71 and 0.33 for surface water and groundwater systems respectively.
\end{abstract}

\section{INTRODUCTION}

High levels of arsenic (As) have been reported both in surface water and groundwater in several African countries (Ahoulé et al., 2015). The source, distribution and mobilization of As in aqueous environment differs by country and within same country differs by location and are associated with either geogenic or anthropogenic processes. Elevated concentrations of As has been reported in the northern part of Tanzania, particularly around the Lake Victoria Goldfields (LVGF) (Mnali, 2001; Lucca et al., 2017) within Lake Victoria Basin (LVB). In the LVGF, large spatial variability of As occurrence has been identified in terms of concentration as well as speciation which hinders meaningful conclusion on its fate based on the available database (Kassenga \& Mato, 2008). The present study aims to investigate: i) the effects of local geological settings on the distribution of As and its concentrations in the drinking water sources; ii) the effects of climate on the variability of As in water sources; and iii) understand the probable links of the adverse health outcomes (viz. cancer cases) due to long term ingestion of inorganic As in drinking water sources in the region. In this abstracts results on spatial variability of arsenic occurrence with respect to local geological setting are presented.

\section{MATERIALS AND METHODS}

\subsection{Study area}

Lake Victoria Basin, Tanzanian part, is one of the 9 river basins in Tanzania mainland covering area of $119,442 \mathrm{~km}^{2}$. The region has little seasonal variation but the eastern sections where Mara region, the study area lies, average only $750-1000 \mathrm{~mm}$ of rain. Favourable climatic conditions for agriculture and livestock and the abundance of natural resources have supported the livlihood of the rural population of over 35 million people (Lucca et al., 2017). The geology of the Tanzanian LBV consists of Archean granitoids-greenstone belts hosted in the Tanzanian Craton. More than $80 \%$ of rural population depends on groundwater resources for various use.

\subsection{Assessment of drinking water supply points in Lake Victoria Basin with respect to local geology}

More than $80 \%$ of rural population in LVB depend on groundwater resources abstracted through boreholes, springs, shallow wells and deep wells. Approximately $50 \%$ of abstraction points target aquifers composed of migmatite-granitoid-metasediment complex, metasediments ( $\sim 22 \%)$, sandy, gravelly, silty sediments $(\sim 10 \%)$, mafic volcanics, meta-basalts, phyllite-greenstone belt with BIF ( $\sim 9 \%)$. The remaining $10 \%$ of groundwater abstraction points target aquifers characterized by the 8 remaining local geological units.

\subsection{Water sampling and laboratory analysis}

Water sampling was carried out at the end of dry season during October 2016. A total of 29 water samples were collected, of which 18 samples were taken from groundwater sources and 11 samples from surface 


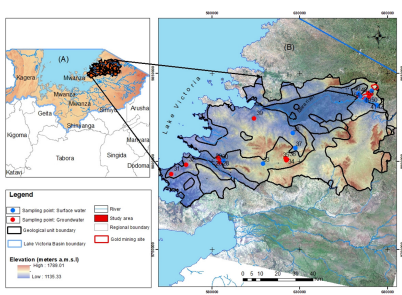

Figure 1. Study area (A) and water sampling locations (B).

water sources were collected (Fig. 1). The physiochemical parameters such as, $\mathrm{pH}$, temperature $(\mathrm{T})$, electrical conductivity (EC), redox potential (Eh) and elevation $(\mathrm{H})$ were measured in the field. Major anions were analyzed by ion chromatography (IC Dionex DX-120) in the Land and Water Resources Engineering laboratory at KTH Royal Institute of Technology. Major cations were determined by inductively coupled plasma-optical emission spectrometry (ICP-OES) at Linköping University in the Department of Thematic Studies.

\subsection{Creation of spatial database and data analysis}

ArcGIS software was used to create spatial database comprising the location and description of each water sample, physio-chemical parameters and major ions and As. The data analysis part involved calculating and mapping of summary statistics, i.e. minimum, maximum, average, and standard deviation.

\section{RESULTS AND DISCUSSION}

\subsection{Spatial exploration of water quality parameters with local geological settings}

The collected water samples were from abstraction points targeting aquifers with following sediment types: i) predominantly alluvial and eluvial sediments (aQ) with slightly alkaline $\mathrm{pH}$ (7.4) and high Eh $($ mean $+416 \mathrm{mV})$; ii) migmatite-granitoid-metasediment complex (miNA) with neutral $\mathrm{pH}$ (7.0) and higher Eh $(356.4 \mathrm{mV}$ mean); and iii) volcanosedimentary complex-Greenstone Belt with banded iron formation (BIF) with approximately neutral $\mathrm{pH}$ (6.9). The higher EC values between 715 and $843 \mu \mathrm{S} / \mathrm{cm}$ indicate that aquifer sediments originate from the parent rocks in Tanzanian Craton. Similarly, the higher mean Eh values between $356-416 \mathrm{mV}$ suggest an oxidizing environment in all geologic units.

\subsection{Probability of occurrence of arsenic contamination in groundwater}

The probability of having contaminated aquifers was calculated based on number of samples with arsenic concentrations exceeding WHO guideline value constrained by local geologic units. Figure 2 shows a probability map of potential arsenic contaminated aquifers.

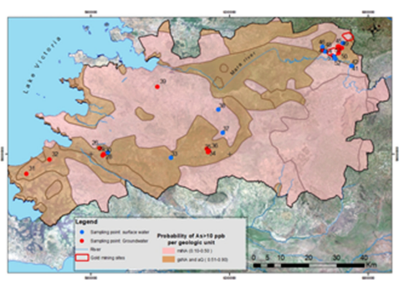

Figure 2. Probability map of arsenic contaminated drinking water sources in Lake Victoria Gold Fields in Mara region.

The most probable aquifers with As levels exceeding $10 \mu \mathrm{g} \mathrm{L}^{-1}$ are found in the lithologic groups aQ and gsNA rocks/sediments (50-90\%). Aquifers in the migmatite-granitoid-meta-sediment complex (miNA) indicate comparatively less likelihood of elevated levels of As in well water. However, this is just a preliminary observation based on the small sample size, and work is currently in progress to link the overall hydrogeochemical characteristics, such as major ions, As and other trace elements with the mapped geological units.

\section{CONCLUSIONS AND RECOMMENDATIONS}

Arsenic contamination in Lake Victoria Basin is a really problem in drinking water sources. The most targeted aquifers composed of migmatite-granitoidmetasediment complex and metasediments seem to have high levels of arsenic exceeding WHO guideline. The drilling practice during potable water supply should consider the type of geological units and sediments to avoid continual exposure to arsenic toxicity among Lake Victoria Basin communities. The behaviour of excess arsenic needs to be investigated with respect to seasonal variations and depth.

\section{ACKNOWLEDGEMENTS}

We acknowledge the Swedish International Development Cooperation Agency (Sida) for supporting the DAFWAT program (Contribution: 51170072).

\section{REFERENCES}

Ahoulé, D.G., Lalanne, F., Mendret, J., Brosillon, S. \& Maïga, A.H. 2015. Arsenic in African waters: a review. Wat. Air Soil Poll. 226(9): 302.

Kassenga, G.R. \& Mato, R.R. 2008. Arsenic contamination levels in drinking water sources in mining areas in Lake Victoria Basin, Tanzania, and its removal using stabilized ferralsols. Int. J. Biol. Chem. Sci. 2(4): 389-400.

Lucca, E. 2017. Geochemical Investigation of Arsenic in Drinking Water Sources in Proximity of Gold Mining Areas in the Lake Victoria Basin, in Tanzania. MSc Thesis, TRITA SEED-EX 2017:25, KTH Royal Institute of Technology, Sweden, 98p.

Mnali, S. 2001. Assessment of heavy metal pollution in the Lupa gold field, SW Tanzania. Tanzania J. Sci. 27(2): 15-22. 